\title{
OS PROFESSORES E SEUS MECANISMOS DE FUGA E ENFRENTAMENTO
}

TEACHERS AND THEIR ESCAPE AND COPING MECHANISMS

Gideon Borges dos Santos ${ }^{1}$

Resumo A partir de exemplos concretos reunidos ao longo de dois anos de estudo sobre a saúde docente, este artigo propõe uma discussão sobre as estratégias que professores constroem para enfrentar as adversidades do cotidiano escolar. Com a utilização dos conceitos de saúde e da psicodinâmica do trabalho, busca-se refletir de que modo os docentes enfrentam adversidades como a não aprendizagem, o comportamento indisciplinado dos alunos, a falta de material didático-pedagógico e o cansaço ou a indisposição para ministrar as aulas. Essas estratégias - denominadas de enfrentamento e de fuga que seriam, aparentemente, promotoras de aprendizagens, também são atividades que reduzem o desgaste dos professores, o que leva à banalização do processo educacional.

Palavras-chave saúde; docência; estratégia.

Abstract Taken from concrete examples gathered over two years of study on the health of teachers, this article proposes a discussion about the strategies that teachers create to face the adversities of everyday school life. With the use of concepts of health and psychodynamics of work, we try to reflect on how teachers deal with adversities such as learning difficulties, the undisciplined behavior of students, the lack of teaching resources, and the teachers fatigue or unwillingness to teach the classes. These strategies - known as coping and escape strategies which would apparently enhance learning, are also activities that reduce the teacher's burnout, which leads to the trivialization of the educational process. Keywords health; teaching; strategy. 


\section{Introdução}

Como entender a produção de saúde em professores nas organizações escolares, partindo da tensão existente entre a organização do trabalho pedagógico e a ação docente? Avaliar o estado de saúde de um indivíduo ou grupo social é algo muito complexo, na medida em que fatores de ordem biológica não são os únicos que interferem ou determinam o estado saudável. Helmam (1994) destaca os aspectos culturais na epidemiologia da doença, tais como a situação socioeconômica, o comportamento sexual, os hábitos de determinado grupo social, a alimentação, as condições de moradia, o uso de confortos químicos, as atividades de lazer, a automedicação e as terapias leigas, dentre tantos outros aspectos produzidos culturalmente, fundamentais na promoção e/ou no agravo da saúde.

Não pretendemos abordar a dimensão biológica e cultural da saúde, embora as reconheçamos como necessárias para um entendimento mais completo do que seja um organismo saudável. Também não serão tratados fatores de adoecimento dos professores, ainda que sejam uma questão amplamente debatida no universo das investigações sobre saúde e trabalho. Abordaremos o movimento de saúde como um campo político, de negociações, que o organismo cria visando à manutenção do equilíbrio considerado, dentro de uma normatividade, um estado socialmente saudável. O conceito de normatividade, cunhado por Canguilhem (2000), relaciona-se com a capacidade que os organismos têm de criar novas normas de comportamento para dar conta da vida.

A preocupação com a saúde do professor nasce a partir da minha atuação como professor de Educação Fundamental. Era comum observar nos pares um desgaste com relação ao exercício profissional, mediante frases do tipo: "Eu não aguento mais esses alunos", "Estou doido para que o ano acabe logo", "Esses alunos não querem nada", "Nossa! Como as férias foram curtas", ditas ainda no início do ano letivo, que poderiam ser evidências de um esgotamento profissional resultante da atividade docente. Ao final do ano, as frases revelavam uma fadiga ainda maior: "Que inferno!", "Esse período é de muito desgaste para a gente", "Estou querendo é paz", diziam os profissionais do ensino.

Todavia, os professores continuavam realizando suas atividades e, até certo ponto, davam conta do que se propunham a fazer. Então, alguns mecanismos eram criados por eles para permanecerem naquela situação e torná-la menos agressiva aos seus corpos e subjetividades. Essas evidências empíricas conduziram à investigação da dinâmica desses mecanismos que permitiam aos docentes continuar dia após dia no exercício da profissão, apesar de conviverem com um 'esgotamento' físico e psíquico diante da atividade de trabalho. Via de regra, esses mecanismos estavam ligados às 
normas rígidas ou flexíveis colocadas pela organização do trabalho que permitem ao sujeito, em maior ou menor grau, negociar as suas expectativas, necessidades, aptidões e anseios, às necessidades da instituição escolar.

Os docentes enfrentam inúmeras adversidades no cotidiano de sua atividade. A pesquisa mostrou que a não aprendizagem, o comportamento indisciplinado dos alunos, a falta de material didático pedagógico, o cansaço ou a indisposição para ministrar as aulas são as mais frequentes. Neste artigo, 2 busca-se refletir quais mecanismos, individual e coletivamente, os professores constroem para enfrentar essas adversidades e de que modo esses mecanismos operam com a finalidade de manter a saúde dos educadores, evitando assim o adoecimento deles ao lidar com as dificuldades impostas pelo ambiente escolar. Esses mecanismos operam sob dois modos contraditórios: servem tanto para promover as aprendizagens dos alunos como também para evitar o desgaste dos professores. Esta situação, ainda que colocada de modo dicotômico, é, na verdade, contraditória, pois um mesmo professor pode realizar os dois movimentos, o de fuga e o de enfrentamento. Uma série de fatores se relaciona com esse movimento, mas a pesquisa, por limitações metodológicas, não pode explicitá-los.

Trataremos de apontar inicialmente o conceito de saúde dentro de uma perspectiva dinâmica, para além da oposição com o adoecimento. Em seguida, é abordado o movimento da saúde dos indivíduos nas organizações e depois feita a descrição do processo de pesquisa, até, finalmente, serem relacionados os conceitos de saúde com os mecanismos criados pelos professores, especialmente as dificuldades da atividade docente e os seus mecanismos de fuga e enfrentamento para lidar com essas adversidades visando à manutenção da saúde.

\section{O movimento saúde-doença}

É sempre mais fácil falar da doença do que da saúde. Os indicadores da doença são mais pontuais, localizáveis e externáveis do que os indicadores da saúde, pois estes envolvem uma multiplicidade de olhares e contextos. Quando Leriche (apud Canguilhem, 2000) afirma que a saúde é a vida no silêncio dos órgãos, corrobora com a ideia de que a disposição do organismo só se torna um problema, uma preocupação, quando está ameaçada.

A relação entre saúde e normalidade focaliza preocupações que buscam compreender como os indivíduos mobilizam suas inteligências em busca de estratégias para lutar contra as adversidades do cotidiano, as doenças, a loucura e a morte. Nessa perspectiva, a normalidade não é um atributo dado, e sim um movimento de defesas operadas, individual e coletivamente, visando à proteção e garantia da integridade física e mental dos organismos. 
Canguilhem (2000) entende que a saúde não é simplesmente ausência de doença ou alterações quantitativas e qualitativas nos organismos, bem como a inconsciência do corpo, mas a capacidade que o organismo tem de, ao estar doente, criar condições em busca da cura; um luxo biológico de se poder adoecer e se restabelecer.

A doença é outra norma que altera o funcionamento do organismo, atrofiando sua interação com o sistema vivo, e a saúde implica criar um movimento para se restabelecer ou instituir novas normas de interação e influência mútua com o meio. Em termos de normatividade, a saúde significa uma norma de vida superior, enquanto a doença, um modo de vida inferior. Para Canguilhem (2000), a saúde de um organismo está na capacidade normativa que ele tem de instituir outras normas de vida e de interação com o ambiente.

O contexto sócio-histórico é um amplo definidor de saúde e doença. O homem é capaz de se modificar e alterar esse contexto, pois avalia as transformações ocorridas no ambiente e sofre as suas consequências, sentindo-se capaz ou não de se adaptar às novas situações impostas pelo cotidiano. “O homem é são na medida em que é normativo em relação às flutuações de seu meio" (Canguilhem, 2000, p. 188).

A saúde é um modus vivendi de ordem singular. Cada indivíduo, cada grupo, tem a sua própria medida a respeito do que seja um estado saudável. Neves e Athayde entendem que o conceito de saúde deve partir:

Da vitalidade do ser vivo, [da] busca permanente de mobilização das forças ativas, de tirar de dentro de si, das suas raízes, as energias necessárias ao viver: inteligência e afetividade para dar conta das exigências e pressões do trabalho. Desse modo, falar de saúde é falar de um cotidiano que demanda ininterruptamente uma mobilização de corpo e alma, de energia, de sangue, de ossos, de músculos, de memória, de desejos, de ódios... Saúde não é um estado ideal, mas algo que se altera todo tempo, que vai estar sempre à nossa frente. Então, saúde é antes de mais nada uma sucessão de compromissos que as pessoas assumem com a realidade, e que se alteram, que se reconquistam, se redefinem a cada momento, se defendem a cada instante. Por fim, saúde é um campo de negociação cotidiana e permanente para tornar a vida viável (Neves e Athayde, 1998, p. 31-32).

É necessário reconhecer que, de modo singular, cada indivíduo ou grupo busca encontrar na vida mecanismos de enfrentamento para as adversidades do cotidiano. Desta forma, mantém a integridade, diga-se saúde, física e mental. Em síntese, entender o movimento de saúde dos indivíduos nas organizações implica considerar suas idiossincrasias e os modos de interação nesses espaços organizacionais. 


\section{Quando o trabalho é obstáculo para a saúde}

Não é pertinente afirmar que a saúde do trabalhador depende exclusivamente da sua condição como indivíduo ou mesmo das condições desfavoráveis disponibilizadas pela instituição. Depende, sim, de um jogo movimentado na relação, na forma como um e outro integram o espaço organizacional.

No movimento saúde-trabalho, satisfação-insatisfação, sofrimentoprazer, os indivíduos mobilizam suas inteligências e seus recursos disponíveis na busca de soluções criativas para tornar a atividade desenvolvida possível e, ao mesmo tempo, para obter resultados positivos no exercício dessa atividade.

Os sujeitos também se mobilizam no sentido de preservar sua integridade física e psíquica, endurecendo-se afetivamente, não se sensibilizando com os problemas insurgidos no trabalho, não se sentindo responsáveis por eles, não se mobilizando em buscar soluções, mas se defendendo de um ambiente que o agride.

Dejours (1996) vai referendar a primeira situação como sendo um sofrimento criativo e a segunda, sofrimento patogênico, dizendo:

Às vezes, em sua luta contra o sofrimento, o sujeito chega a elaborar soluções originais que (...) são em geral favoráveis simultaneamente à produção e à saúde: caracterizamos esse sofrimento denominando-o sofrimento criativo. Ao contrário, nessa luta contra ao sofrimento, o sujeito pode chegar a soluções desfavoráveis à produção e desfavoráveis também à sua saúde. O sofrimento então qualificado como sofrimento patogênico (Dejours, 1996, p. 150, grifos do autor).

A partir do sofrimento, os sujeitos podem elaborar estratégias de enfrentamento e de fuga que se caracterizam como recursos para uma convivência saudável no espaço organizacional. No primeiro caso, para o sujeito enfrentar as adversidades encontrando satisfação na atividade realizada, e no segundo, para não se desgastar, poupando energia, e para não se desestruturar física e psiquicamente. Porém, as estratégias defensivas só se configurarão como mecanismo de saúde quando parte da energia pulsional oriunda da tensão do sofrimento é canalizada para algo socialmente produtivo. A permanência do sujeito no uso de estratégias de fuga pode levá-lo ao adoecimento psicossomático, na medida em que a realização da atividade é esvaziada de sentido. Esse campo de negociações é forjado nas malhas da organização do trabalho.

A organização do trabalho comporta a divisão do trabalho - o conteúdo ergonômico da tarefa e o sistema hierárquico -, as modalidades de comando, as relações de poder, as responsabilidades atribuídas... Segundo Dejours, é preciso entendê-la como sendo, 
de uma parte, a divisão das tarefas (chegando à definição do modo operatório) que atinge diretamente a questão do interesse e do tédio no trabalho; de outra parte, a divisão dos homens (hierarquia, comando, submissão), que atinge diretamente as relações que os trabalhadores estabelecem entre si no próprio local de trabalho (Dejours, 1996, p. 153).

Para Dejours (1992), o trabalho adquire sentido adoecedor quando sua organização não permite ao trabalhador emprestar sua subjetividade à atividade realizada e construir um modelo de gestão paralela para conseguir sobreviver naquele ambiente de modo mais ou menos saudável.

A livre organização do trabalho torna-se peça essencial do equilíbrio psicossomático e da satisfação (...). A organização rígida e imposta, que caracteriza a maior parte das tarefas industriais, aparece, inicialmente, como um obstáculo a uma livre estruturação da tarefa (...) quanto mais rígida for a organização do trabalho, menos ela facilitará a instrumentação favorável à economia psicossomática individual (Dejours, 1992, p. 128).

Aqui cabem alguns questionamentos: quais estratégias os professores constroem para enfrentar as adversidades do cotidiano escolar? Em que medida essas estratégias podem significar um dispositivo de promoção de saúde? E para a escola e o processo pedagógico, quais consequências podem ser atribuídas como decorrentes das estratégias criadas por professores no movimento de saúde?

\section{Sujeitos, contextos, trajetórias}

A escola que se tornou cenário desta pesquisa faz parte do quadro de escolas municipais da cidade de Salvador, Bahia. Trata-se de uma escola que agrega, num mesmo espaço, alunos do Ensino Fundamental do primeiro ao nono ano, diferentemente da maioria das escolas locais, que atendem crianças do primeiro ao quinto ano ou do sexto ao nono ano.

A abordagem metodológica adotada teve na etnografia a inspiração para orientar e fertilizar as análises e discussões aqui propostas, com o objetivo de compreender as redes de relações do cotidiano, destacando as estratégias que professores constroem e os modos como as legitimam nos espaços da vida escolar, visando à manutenção da saúde.

A maior parte do material da pesquisa foi construída a partir de três momentos. Em todos eles, usou-se o diário de campo. Primeiramente, foram feitas observações com os professores, coordenadores e diretores, quarenta no total, em três situações cotidianas do seu trabalho: nos intervalos de 
aula, nas reuniões pedagógicas, nos horários de almoço $^{3}$ e nos eventos comemorativos ${ }^{4}$ realizados pela escola. Muito mais do que observar os docentes individualmente, procuramos descrever o modo como eles interagiam nos espaços escolares. Nesses ambientes, eles falaram sobre tudo o que lhes acontece na escola e na vida pessoal. De confessionário a muro das lamentações, esses espaços equivaliam a um diário oral do que acontece nos bastidores da escola.

No segundo momento de investigação, buscamos extrair informações a partir da análise dos documentos que organizam o trabalho pedagógico. São eles: regimentos escolares e decretos, Planos de Desenvolvimento Escolar do período de 2001 a 2003, planos de capacitação pedagógica referente aos anos de 2001 e 2003,5 quadro de horário de 2003, quadro de distribuição de disciplinas de 2003, mapas de aprendizagem de 2003, atestados médicos do período de 1997 a 2003,6 além de três bilhetes, encontrados entre os documentos, escritos por professores(as) e dirigidos à direção e aos colegas, pedindo que alguém os substituísse na aula.

No terceiro momento, aprofundamos questões relacionadas à investigação, insurgidas no contexto da observação e da análise documental, mediante entrevistas que foram realizadas com oito professores. As entrevistas foram semiestruturadas e realizadas mediante roteiro. O roteiro de entrevista foi entregue previamente ao entrevistado para que este pudesse refletir sobre o objeto de estudo desta pesquisa e, assim, otimizar as informações (Costa, 1995).

Procedida a construção do material de pesquisa, foi efetuada a sua análise. Foi utilizada, portanto, a técnica de agrupamento dos dados em categorias de codificação que se estabeleceram a posteriori (Bogdan e Biklen, 1994), obedecendo aos seguintes critérios: pela recorrência nas falas dos depoentes, pelas semelhanças existentes entre essas falas e, mesmo com baixa recorrência, pela significação que essas unidades traziam para o entendimento da questão.

A análise do material obedeceu à seguinte ordem: entrevista, documentos, observação e diário de campo. O fato de a entrevista ter sido realizada por último possibilitou o confronto entre as informações nela contidas e as informações nos documentos e na observação.

\section{O cotidiano como invenção}

Ensinar é uma grande invenção. No cotidiano, os professores criam atividades, julgadas por eles como diferentes alternativas ao modo convencional de lecionar. Frente a situações de não aprendizagem, comportamento indisciplinado dos alunos, falta de material didático pedagógico, cansaço ou 
indisposição, os docentes criam modos alternativos de ministrar as aulas. Entretanto, muitas dessas atividades que seriam, aparentemente, promotoras de aprendizagens são, também, atividades que reduzem o desgaste dos professores. São as estratégias de enfrentamento e de fuga.

\section{Nós temos que improvisar}

Eu improviso. Você tem de improvisar na sala de aula, porque muitas vezes não tem material. Você faz um planejamento, mas, chega na hora, a escola não reproduziu o texto porque não tinha folha de papel. Quer dizer, você tem de improvisar o que ia fazer na sala de aula. Pede a xerox, não tem como conseguir. Você acaba improvisando (Entrevista 4).

Eu procuro trazer sempre coisas novas, eu não fico só naquela aula expositiva. Sempre trago coisas novas. Dependendo do assunto, a gente começa a conversar, a dar exemplos (...). Eu procuro trazer jogos, caça-palavras, palavras-cruzadas... Então, procuro diversificar muito o meu conteúdo de maneira que não fique muito cansativo nem para eles, nem para mim (Entrevista 3).

A falta de material pedagógico é um obstáculo sério à ação do professor. Por conta dessa adversidade, é comum o professor permanecer ministrando aulas convencionais, como copiar no quadro e solicitar que o aluno faça a transcrição, ou propor atividades dinâmicas, lúdicas e criativas para os educandos interagirem entre si e obterem o máximo de aprendizagem.

Uma destas atividades é o trabalho em grupo. O professor, fugindo à aula expositiva tradicional, cria situações de aprendizagem para estar junto aos discentes observando-os, discutindo com eles, intervindo na atividade de ensino-aprendizagem, acompanhando-os, tirando-lhes as dúvidas, fomentando novos questionamentos, promovendo a aprendizagem do conteúdo proposto.

Além disso, essa mesma atividade pode ser utilizada como preenchimento do tempo de aula. Enquanto os alunos estão reunidos em grupo, em sala de aula, o professor aproveita esses momentos para ficar nos corredores da escola conversando com o colega ou para permanecer sentado em sua cadeira vendo algum outro material, principalmente corrigindo provas de outras turmas, enquanto os alunos, sozinhos, desempenham a atividade proposta.

O exercício em grupo tanto pode servir como estratégia de interação, construção de conhecimento, levantamento de dúvidas e atenção mais especial aos alunos com maiores dificuldades de aprendizagem e de relacionamento, como também pode ser utilizada pelo professor como 
recurso para realizar outras tarefas, ou mesmo como uma distração do enfado cotidiano. ${ }^{7}$

\section{Criando pressões, vencendo obstáculos}

Chamo a atenção com calma, às vezes com brigas, entendeu? Às vezes faço um terrorzinho para chamar a atenção. Às vezes converso sobre a necessidade de estudar. Não é só jogar, não é só brincar... Eles têm direito a tudo isso. A meu ver é importante, mas eles têm de ter a responsabilidade de aprender alguma coisa. Eles têm de ter conhecimento para reivindicar, lutar por seus direitos e não deixar tudo nas mãos dos outros. O conhecimento é muito importante. Eu luto para que eles se conscientizem dessa importância (Entrevista 6).

Eu acho que sou muito bruto, mas se eu deixar de ser eles me cobram. Eles dizem assim: "O professor está ficando mole, já está ficando velho..." Mas eu deixo para lá. Não é toda vez também que se vai pegar no pé. Ficar falando "cale a boca" enche o saco, sabe? Não é toda hora, não (Entrevista 1).

Então, tem hora que você tem de desprezar certas coisas, tem de usar dessas estratégias que você usa até com o filho. Tem de desprezar mesmo (Entrevista 7).

Os professores, de modo geral, demonstram preocupações com seus alunos. Conversam com colegas para saber a situação socioeducativa dos educandos com relação a outras disciplinas, trocam informações sobre o comportamento deles e características de suas personalidades. Essa necessidade de fazer comparações é uma alternativa para os professores não se sentirem culpados pelo baixo rendimento dos alunos, caso estes tenham desempenho e comportamento semelhantes em outras disciplinas.

Frente ao suposto desinteresse pela escola e baixo rendimento de aprendizagem, e diante do (des)respeito dos alunos, os professores costumam recorrer a determinadas estratégias das mais tradicionais às mais sui generis: aplicar testes surpresas ao final de cada exposição de um conteúdo; oferecer um prêmio ao final de cada unidade, semestre ou ano letivo aos alunos que tiverem melhor desempenho nas notas ou ao aluno que permanecer mais bem comportado durante o ano. Outras vezes, utilizam o dispositivo da nota, ameaçando com zero na prova ou reprovação para pressionar os alunos a se comportarem melhor e a se interessarem mais pelos estudos. ${ }^{8}$ São ainda comuns procedimentos como dar advertências orais, ${ }^{9}$ fazer de conta que não está vendo qualquer atitude dos alunos considerada inadequada, visando a não se desgastar, despender o menor esforço possível, evitar aborrecimentos ou mesmo não permitir um clima afetivo desfavorável e levar o 
problema para ser resolvido pela autoridade superior, como direção escolar e pais. Semelhante análise fizeram Noronha, Assunção e Oliveira (2008, p. 75), ao estudarem o caso de professoras da rede pública de Montes Claros, Minas Gerais. Segundo as autoras, "há um momento em que elas [as professoras] ignoram os eventos da indisciplina, parecendo expressar uma estratégia para lidar, no seu limite, com o cansaço e os seus efeitos. $\mathrm{O}$ aparente desligamento seria uma manifestação de sofrimento (...)". No caso da escola baiana, esse tipo de atitude é utilizado quando todas as outras já se esgotaram e, sendo assim, o desfecho é, frequentemente, a suspensão temporária dos alunos das atividades escolares.

De repente, o alarme toca. Os alunos invadem os corredores da escola. Eles gritam, pulam, demonstram contentamento. A professora, como espectadora, de longe observa. Eu me aproximo dela, que diz: "Tenho de dar aulas no nono ano, mas não vou me meter nessa confusão." Todo movimento dos alunos era por conta de uma atividade que estava sendo desenvolvida na aula de História. A atividade envolvia colagem. Um aluno espalhou cola de papel na cadeira do colega, espreitando se ele sentaria nela, o que de fato ocorreu. O professor, decidido a encontrar o responsável pela travessura, para a atividade e pede que ele se apresente. Não conseguindo identificá-lo, mas imbuído do desejo de encontrar o culpado, resolve chamar a direção da escola. O diretor vai até a sala de aula: "O culpado tem de aparecer." Não o encontrou. Ameaça a turma de suspensão por três dias. "Mas a gente vai fazer prova", alguém diz. "Problema!", responde o diretor. Como ninguém decide entregar o autor da peripécia, decretou: "O nono ano, turno matutino, está suspenso por três dias." Com alvoroço e felicidade, os alunos invadem os corredores da escola gritando. Aproximam-se da professora e relatam o acontecido, acrescentando: "Que bom! Uma semana de feriado." Nesse momento, um aluno se dá conta da prova e pergunta à professora o que fazer. Ela diz: "Estão vendo, bem que eu avisei: Gente, se comportem! Agora, deu no que deu." De repente, alguém grita no final do corredor: "A turma não foi suspensa, não. O culpado apareceu. Foi o Tiago." Os alunos voltaram para a aula e o autor da travessura foi para a sala do diretor que, após longa conversa recheada de sermões, o suspendeu por três dias das atividades escolares (Diário de campo, 24 de abril de 2003). 10

Os alunos não acreditam na escola e os professores estão sem argumentos para demonstrar a importância do estudo, talvez por também duvidarem disso. A suspensão dos alunos das atividades, que seria uma espécie de castigo, significa para eles uma premiação: se afastar compulsoriamente da escola. E o diretor e o professor, por sua vez, livram-se do problema temporariamente. Dessa forma, a escola segue dia após dia tentando vencer as dificuldades com paliativos e placebos. A crise sem precedente que as insti- 
tuições escolares públicas estão vivendo suscita em alunos, professores e sociedade em geral uma descrença generalizada.

\section{Intervalo, por favor!}

O início é sempre esperado; o fim, indesejado. Bate a sirene da escola. Hora de intervalo. O espaço escolar entra numa nova dinâmica: alunos correm, pulam, gritam pelos corredores... Parecem estar felizes. Professores chegando em sua sala. Sentam-se. O café já está à espera deles. Um bate-papo é sempre bom. Uma conversa qualquer. Assuntos não lhes faltam. Sempre têm o que falar. Outro professor chega, e outro, e outro... A expressão de espera por aquele momento é visível. Mais um tempo e a sala está cheia. A conversa, a brincadeira, o riso tomam conta daquele espaço. Eles falam sobre tudo. O momento é rápido e alguém anuncia o final daquele tempo: "Por um momento esqueci que vou dar aula." A sirene toca. É hora de voltar. O fim chegou. O desejo de que não chegasse é notável. Alguém se levanta, arruma o material e segue como quem suspira ao enfrentar a batalha: é a sala de aula que o chama. Outro retarda o tempo. Tenta fingir que não acabou, ampliar aqueles momentos que, embora diários, rapidamente se passam. Lentamente, todos voltam. Aquela sala fica vazia. O intervalo já se perdeu. Agora, é esperar o amanhã. A cena se repetirá (Diário de campo, 28 de maio de 2004).

Você iria se escandalizar porque o horário é às 19 horas. Chegue aqui de surpresa para eu lhe provar. Se reuniu [o professor], entrou em acordo que o horário de aula é às 19 horas, por que o professor só entra na sala de aula às 20 horas, já na hora de ir embora? (Entrevista 1).

O intervalo significa para muitos professores um recurso de 'fuga' das adversidades cotidianas. Chamarei de intervalo o curto espaço de tempo entre a chegada na escola e a entrada na sala de aula, entre uma aula e outra na existência de horários vagos e o horário do lanche. Nessas horas em que os professores demonstram muita alegria, descontração e satisfação em estar na escola. Esses momentos se apresentam da seguinte forma: a) prolongamento do tempo de entrada na sala de aula com a consequente redução do tempo de exercício da docência;11 b) acordos, muitas vezes não cumpridos, de permutar o intervalo para antecipar o término da aula; c) prolongamento do intervalo, que é de dez minutos, para quanto tempo for possível, reduzindo cada vez mais o tempo de se defrontar com a sala de aula e com os problemas que advêm dela.

A transformação dos intervalos em momentos criativos, de prazer, de satisfação, é uma alternativa à rigidez da organização, prescrita por suas 
regras e seus compromissos, que são sufocantes e impedem o exercício pleno do viver. O intervalo é, para muitos professores - e também para os alunos -, o momento para 'respirar'. É como se o viver, na escola, ficasse restrito exclusivamente aos intervalos.

A expressão "por um momento esqueci que vou dar aula" evidencia o quanto a sala de aula é enfadonha e desgastante e o quanto o intervalo é prazeroso. Por que a sala de aula se tornou um fardo para alunos e professores, a ponto de ser evitada no prolongamento do intervalo? Não tenho resposta para essa questão, mas percebo nela uma situação paradoxal. Os professores 'evitam' a sala de aula e, para isso, utilizam-se do intervalo, por considerá-lo prazeroso. O paradoxo está no fato de transformarem esses momentos em encontros prolongados, suprimindo o seu sentido de inspiração para retornar à sala de aula. Evitar a sala indica, propriamente, uma fuga ao que causa desprazer aos professores e alunos. Supostamente, o intervalo é que indica um momento de liberdade, descontração, diálogo e espontaneidade que, talvez, não seja cultivado em sala de aula. Se, para uns professores, o intervalo é apenas um momento de prazer inspirador para reiniciar as aulas, para outros acaba se configurando a própria, e talvez única, atividade de prazer que eles encontram frente à atividade docente.

\section{Afastando-se das atividades}

A atitude de se afastar das atividades escolares seria de ordem física e psicológica. No primeiro caso, não estando presente no ambiente de trabalho e, no segundo, não se sentindo envolvido nele, podendo se manifestar da seguinte forma: via atestado médico. Se somássemos a quantidade de dias de liberação, por motivo de saúde, que os professores da escola pesquisada tiveram, desde 1998 até julho de 2003, teríamos um total de 1.212 dias. Se a proporção for correspondente, poderíamos dizer que, a cada grupo de quarenta professores, pelo menos um poderia ser contratado por um ano letivo e pago com o que se gasta com a liberação de professores através desse recurso.

Os atestados geram dúvidas quanto à sua veracidade, pelo seu grande número, o que merece uma consideração. O levantamento dos atestados médicos apresentados por professores nesse período (esse número pode ainda ser maior, já que, segundo a direção da escola, a organização do arquivo data de 2000, o que significa a perda de algumas informações) revela os seguintes dados:

- No ano de 1998, foram apresentados pelos professores 29 atestados médicos, sendo 55\% deles justificando a ausência de um dia às atividades escolares. 
- Já em 1999, o número foi reduzido para 17 atestados. Destes, 41 \% solicitando afastamento dos professores das atividades. Esse afastamento varia de dois a trinta dias.

- Em 2000, os professores apresentaram 41 atestados, dos quais 65\%, aproximadamente, justificando ausência de um dia ou turno de trabalho e $35 \%$ solicitando afastamento das atividades que variava de dois a sessenta dias.

- Em 2001, foram apresentados 91 atestados em proporções semelhantes aos anos anteriores. Já no ano de 2002, esse número caiu para 84 . Porém, aumentaram os dias de afastamento ao trabalho. Se somássemos o número de dias de afastamento de professores ao trabalho nesse ano, conforme os atestados médicos, teríamos o total de 458 dias. É o equivalente a um professor ficar cerca de um ano e meio sem trabalhar. Ainda em 2002, só de atestados pedindo liberação de professores por trinta dias foram sete, quase $10 \%$ do total. - No ano de 2003, até julho, foram identificados 65 atestados, e 49 deles são pedidos de liberação por um dia de trabalho, portanto, a maioria. Dos atestados médicos dados, 194 são relativos a exames e/ou consultas realizadas por professores; 104 pedem afastamento ao trabalho de, no mínimo, dois dias, 15 são relativos a acompanhamento realizado por professores de algum parente, geralmente filhos, e quatro por outros motivos não especificados.

A emissão desses atestados fica sob a responsabilidade de serviços públicos e particulares. Duzentos e nove deles foram emitidos por clínicas odontológicas, otorrinolaringológicas, oftalmológicas, ginecológicas, cardiológicas, de ultrasonografia e outras.

O professor que apresenta atestados médicos sem maiores critérios, apenas para se afastar momentaneamente da atividade, dá um sinal de que algum mal o exercício da docência está lhe causando, a ponto de ele criar determinados mecanismos de fuga. Ou, então, é sinal de que ele vive em condições adversas que estão colocando em risco a sua saúde. Já o afastamento do professor das atividades por adoecimento sinaliza a questão da salubridade. Em ambos os casos, tem-se um ambiente que agride o sujeito e o coloca diante da possibilidade de construção de mecanismos de enfrentamento e de fuga. Barros (2002, p. 27), realizando estudo sobre os modos de gestão e a produção de subjetividade no trabalho, destaca que as solicitações de afastamento do trabalho por motivos médicos sinalizam ora estratégias que recusam os modos de administração verticalizados, movimentos que buscam fugir das serializações impostas, constituindo-se em importante estratégia política, ora adoecimento e, ainda, defesas que buscam evitar o adoecimento.

Nesta pesquisa, não observei esta dinâmica. Apesar de o número de licenças ser muito grande, também é comum, por exemplo, haver professores que, mesmo estando indispostos ou doentes, se encontram na escola desenvolvendo suas atividades. Isso se dá ou pelo sentimento de vergonha 
em faltar às atividades escolares e ser considerado preguiçoso, indolente, irresponsável, ou, então, porque encontra no ato de ensinar um recurso de luta contra a doença. Ao invés de ficar em casa, sem nada poder fazer, prefere trabalhar. Esse é um recurso de luta contra a doença que pode ser mais eficaz do que permanecer em casa.

\section{A cumplicidade do jogo}

Tem uma negociação. Outro dia mesmo eu estava aqui para participar das aulas unidas $^{12}$ porque a diretora me pediu. Porque, quando eu não posso vir, quando acontece algum problema, eu chego para ela [a diretora] e digo: "Não vai dar para eu vir." Então ela diz: "Não tem problema nenhum." Porque ela sabe que quando precisar de mim pode contar... Tem esse coleguismo. Está entendendo o que estou falando? (Entrevista 4).

Aqui, um quebra o galho do outro. A professora falou: "Sexta-feira não vou poder vir porque tenho que ir ao médico." Eu perguntei: "Qual a atividade que você tinha para fazer?" Você fica e tenta fazer a atividade. Com relação a isso, é excelente. O coleguismo, a participação (...). Quando eu cheguei aqui na escola, por exemplo, não sabia como fazer o planejamento. Um dizia: “Tente fazer dessa forma." E outro: “Tente fazer desse jeito..." (Entrevista 4).

A ideia de cumplicidade condensa bem a forma como professores(as) procuram ajudar uns aos outros, buscando solucionar dificuldades encontradas em seus cotidianos da seguinte forma: a) no apoio que recebem tanto da direção escolar quanto dos colegas para planejar e executar atividades alternativas que promovam aprendizagem dos alunos; b) na barganha feita entre professores e direção;13 c) no apoio, nas confidências e nos aconselhamentos sobre problemas de ordem pessoal e profissional, os professores se solidarizam com as dificuldades vivenciadas, trocam experiências, planejam junto as atividades pedagógicas, compartilham entre si os infortúnios, tornando o ambiente escolar mais aprazível; d) na aproximação da convivência através da organização de eventos. 14

O apoio dado para a realização de atividades, a barganha, os aconselhamentos e as confidências podem ser entendidos ora como movimento de enfrentamento às adversidades, quando promovem o desenvolvimento da organização escolar, ora como movimento de afastamento, à medida que são utilizados para reduzir o desgaste do professor mediante a ação realizada.

Embora a barganha represente todo um esforço para gerenciar questões emergentes da organização do trabalho pedagógico, não posso deixar de sinalizar que tal empenho provoca um desvio da função da docência. 
Os professores, ao invés de discutirem a ação pedagógica, o planejamento escolar, o processo de ensino-aprendizagem, dedicam tempo para suprir as deficiências da instituição. A questão se torna ainda mais complexa quando o teor dessa barganha é associado ao fato de ela significar um recurso para o professor(a) se ausentar da escola e das atividades escolares.

No entanto, a falta de profissionais para desempenhar as atividades de organização dos registros escolares, por exemplo, é um entrave ao desempenho da ação docente, sendo necessário, portanto, buscar dispositivos na resolução do problema. Nesse caso, a saída para solucionar essa dificuldade nasce das entranhas das relações socioafetivas cultivadas no espaço escolar.

Com relação às atividades integradas ao currículo, que buscam promover as relações socioafetivas na escola, o jogo entre o prescrito e o real toma configurações semelhantes. O prescrito pela escola é ministrar aulas. Então, as atividades integradas são estratégias criativas que tornam a escola mais prazerosa para seu público. Soa como uma espécie de 'fuga' à rotina estabelecida pelas organizações de ensino. Essa 'fuga' pode servir tanto como estratégia pedagógica, buscando transformar a escola num ambiente de valorização e aprendizagem para aluno, pais e professores, quanto ser utilizada por estes como estratégia para faltar às atividades docentes ou sair mais cedo do trabalho. Esse tipo de atividade imprime uma nova dinâmica na rotina da escola. Ao invés de ministrarem aulas, os professores realizam jogos, gincanas, mostra pedagógica, feiras etc. Tais atividades 'dispensam' a presença física de todos os professores, permitindo que alguns deles se ausentem da escola para resolver questões particulares, sem implicar retaliações, faltas e advertências. Esse comportamento é possível por dois motivos: pela intimidade, confiança e cumplicidade estabelecida pelo grupo e pelo fato de tal atitude não comprometer o funcionamento da escola.

Essas práticas evidenciam modos alternativos de convivência que se aproximam da cumplicidade, da cooperação, com um propósito de se fortalecerem, buscando beneficiar-se, mas que não encontram legitimidade alguma na organização do trabalho escolar. É uma forma que as pessoas têm de dizer entre si como seus papéis social e profissional são importantes para a sociedade.

A cumplicidade cultivada no ambiente escolar, ao se pôr em prática um projeto com apoio da direção, por exemplo, pode significar mais que a realização de uma ação pedagógica. Trata-se, também, da possibilidade de fortalecimento de alianças construídas no espaço escolar. Quando a direção da escola realizar algo poderá contar com o apoio do professor e vice-versa.

Essas alianças são úteis, pois dinamizam a realização de atividades na escola e legitimam as estratégias construídas por professores, resultando numa relação de economia de energia despendida, caso se tratasse de um ambiente desprovido dessa cumplicidade. A lógica dessa relação, muitas 
vezes utilitarista e pragmática, está nos modos como os professores estabelecem os vínculos com os pares, legitimando a lógica de organização prescrita, o que também é estratégico, uma vez que seguir rigorosamente o prescrito pode significar a não produtividade.

Uma organização do trabalho pedagógico mais flexível, sensível e, portanto, compatível com o conteúdo da ação docente é capaz de permitir ao professor maior e melhor adaptação. Quando a organização do trabalho pedagógico permite ao professor emprestar sua subjetividade à atividade realizada, há maiores possibilidades de adaptação de suas aspirações e competências ao exercício da docência. Uma organização voltada para as necessidades educativas dos sujeitos envolvidos, com inspiração nos princípios de pedagogias que estão sensíveis aos modos singulares como os indivíduos se constroem subjetivamente. Não pretendemos que a organização do trabalho de uma instituição deva acomodar todos os interesses, expectativas e anseios de cada indivíduo. Aliás, isso seria impossível.

É necessária uma organização que considere o professor como agente de educação e não como executor de tarefas; que crie bases para ele pensar e fazer a educação; que redimensione a estética dos espaços educativos, que organize e dinamize a pesquisa como fomento de ensino e que crie significado para uma ação docente contextualizada e significativa, vitalizando o papel do professor de modo que ele encontre significado na realização da ação docente.

\section{Considerações finais}

Até aqui, tentamos apresentar e analisar as estratégias de fuga e de enfrentamento que professores elaboram para vencer as adversidades do cotidiano escolar. Entretanto, a finalização deste trabalho suscita mais dúvidas do que apresenta respostas.

Ao se utilizar formas inventivas de enfrentamento às adversidades, visando a tornar viável o ambiente escolar, os professores demonstram um sinal de responsabilidade, de resistência e de criatividade ao transformar a adversidade em possibilidades de aprendizagens.

Todavia, utilizando-se das estratégias defensivas de afastamento das atividades, seja enganando o tempo, seja promovendo atividades sem propósitos educativos, realizando um ensino irresponsável, o professor está cristalizando na escola a banalização do processo educativo e, muito pior, cerceando a possibilidade de encontrar prazer frente ao ato de ensinar. De fato, os indivíduos sempre criam formas de forjar o cumprimento do prescrito, fazendo de conta que os fatos estão acontecendo, quando, em verdade, realizam outra atividade. 
As estratégias são criativas, pois os professores têm de construir alternativas procurando superar as dificuldades. Instituir estratégias de fuga não significa algo menos criativo. Significa uma necessidade de 'afastamento' da dinâmica escolar visando ao menor esforço. Ambos os movimentos se dão a partir de uma luta estabelecida pelo sujeito buscando encontrar o bem-estar e o equilíbrio frente à atividade realizada.

No movimento de convivência com as adversidades do cotidiano escolar, o que está em jogo é o que provoca maior ou menor desgaste, maior ou menor bem-estar ao professor, ainda que isso comprometa o desempenho do processo educativo. Sai de cena a ideia de que o mais importante é o processo de educação e entra em cena o que oferece melhores possibilidades de equilíbrio biopsicoafetivo ao professor. Todo indivíduo opta pelo seu bemestar. Se a escola não oferece as condições mínimas adequadas de educação, a luta será pela sobrevivência e pelo bem-estar. Cabe ao professor cumprir o prescrito ou, então, criar um modelo paralelo de gestão.

Paradoxalmente, essas atividades fazem parte de um conjunto de estratégias construídas objetivando não o que aparentemente seria a promoção de aprendizagem, mas também um leque de alternativas para tornar a atividade docente menos desgastante. Então, como fica a questão da profissionalidade docente? O compromisso ético que o educador estabelece com sua profissão, com o outro e com o processo educativo? Nesse mesmo sentido, como podemos pensar na dimensão ética que atravessa a profissão? Os acordos feitos por professores têm um sentido cooperativo ou corporativo?

Esses questionamentos me levam a pensar em dois pontos quando o assunto é saúde. Os professores, ao construírem estratégias de fuga, promovem a banalização do processo educativo. 15 Para Dejours, a sociedade criou uma espécie de tolerância para conviver com a miséria do mundo, especialmente relacionada ao trabalho. Convivemos com o sofrimento alheio sem necessariamente nos indignarmos. Essa espécie de tolerância tem afetado a escola. O aluno, que passa um terço de sua vida na escola e sai dela sem aprender o mínimo necessário exigido socialmente, não mais provoca indignação entre educadores. Os professores desenvolveram uma espécie de tolerância para conviver com as adversidades escolares. Só que, ao construírem estratégias de enfrentamento, demonstram compromisso frente ao exercício profissional.

Em primeira instância, os professores buscam modos criativos de tornar o cotidiano dinâmico e dar conta das adversidades enfrentadas. A incidência desses episódios, muitas vezes com resultados abaixo do esperado, cria uma espécie de endurecimento afetivo no professor a ponto de não se identificar com a profissão e com os problemas advindos dela. A questão é que, no caso da docência, tais mecanismos também se configuram como uma defesa para suportar as pressões do dia-a-dia na escola. 
Como considerar, então, um movimento de fuga frente às adversidades, um mecanismo de saúde, se isso interpõe uma desqualificação do trabalho? O professor que não cumpre os compromissos assumidos frente ao trabalho está desprovido de saúde? Por que considerar os mecanismos de fuga como um adoecimento, se essa falta de vitalidade é exclusiva na relação com o trabalho e não com o cotidiano escolar, como, por exemplo, no momento do intervalo, em casa, na família? Nesse sentido, a falta de saúde seria apenas para a realização da atividade profissional? Consideramos que não. A saúde se apresenta no sujeito em sua inteireza e não de modo fragmentado e, quando os professores constroem mecanismos de fuga e enfrentamento, está em jogo a busca pelo bem-estar. É necessário avançarmos na ampliação do próprio conceito de saúde e considerá-lo em sua dimensão ético-política como jogo de negociações.

Esta pesquisa buscou identificar estratégias que professores constroem frente ao exercício da docência. Deve-se ressaltar que, nos complexos mecanismos de fuga e enfrentamento das adversidades do cotidiano escolar, o que está em jogo muitas vezes é um critério de ordem subjetiva que pode retirar de cena o ideário educativo. Há que se interrogar: diante de uma escola que não oferece as condições mínimas adequadas para o processo educativo, a luta pelo bem-estar é o resumo do ato de educar?

\section{Notas}

1 Professor e pesquisador da Escola Nacional de Saúde Pública Sergio Arouca, da Fundação Oswaldo Cruz (Ensp/Fiocruz), Rio de Janeiro, Brasil. Doutorando em Política Pública e Formação Humana, na Universidade do Estado do Rio de Janeiro (Uerj). <gidborges@ensp.fiocruz.br>

Correspondência: Escola Nacional de Saúde Pública Sergio Arouca, Fundação Oswaldo Cruz (Ensp/Fiocruz), Rua Leopoldo Bulhões, 1.480, $3^{\circ}$ andar, sala 314/7B, Manguinhos, Rio de Janeiro, Brasil, CEP 21041-210.

2 Texto apresentado no Congresso Latino-Americano de Estudos sobre Trabalho Docente, em 2006.

3 Boa parte dos professores tem quarenta horas de trabalho nessa escola, o que otimiza a convivência entre eles, já que sempre almoçavam na escola ou num restaurante próximo.

4 Dia do Professor, Dia do Estudante, aniversário da direção, Natal, entre outros.

5 Em 2002, não foi encontrado qualquer documento que fizesse referência à capacitação pedagógica. 
6 Segundo a diretora da escola, muitos dos documentos se perderam, já que a estruturação do arquivo começou a partir do ano 2000, com a atual gestão, o que significa que muitos atestados médicos podem ter sido perdidos.

7 Essas atividades vão exigir do professor um tempo maior de planejamento, de execução e acompanhamento do movimento da turma. Entretanto, na organização prescrita, não há espaço para que elas aconteçam e acabam virando um 'jeitinho'.

8 Essas pressões deixam os alunos intimidados frente a uma reprovação, advertência verbal escrita, até mesmo suspensão da escola.

$9 \mathrm{O}(\mathrm{a})$ professor(a) procura mostrar aos alunos que a formação educacional básica é necessária, mas insuficiente, fortalecendo a ideia de que a escola é o melhor caminho para uma colocação no mercado de trabalho. Utiliza-se do discurso de que a escola prepara para um mercado de trabalho que exige profissionais cada vez mais qualificados. O professor ainda lança mão de informações que abordam a quantidade de desempregados existentes, atribuindo a isso falta de qualificação por não ter estudado. Vale ressaltar que as profissões citadas são, em geral, de formação técnica, como marceneiro, padeiro, garçom, entre outras. O modelo de profissão utilizado para demonstrar a consequência do não estudo, geralmente, é o de gari e empregada doméstica, forjando um discurso e destacando que mesmo esses profissionais precisam estudar para exercerem suas profissões. Acrescentam ainda que, atualmente, em alguns lugares, até para ingressar nessas profissões exige-se Ensino Médio completo. Recorrer à própria história de vida, às dificuldades enfrentadas na época de estudante, também é um recurso para demonstrar a importância de estudar.

10 Enquanto descrevia essa cena, uma professora trouxe uma aluna, arrastada pelo braço, até a sala dos professores, e disse: "Sente aí." A aluna, aparentemente envergonhada, obedeceu como quem espera o castigo. Uma colega se aproximou e a convidou para sair. Ela disse não poder, narrando o episódio. Dois professores chegaram à sala perguntando pelo ocorrido, que é mais uma vez narrado, gerando indignação e mal-estar entre eles. O diretor chegou. A professora disse o que aconteceu. Imediatamente, ele emitiu à aluna uma suspensão de três dias das atividades escolares.

11 Ao chegar à escola, o professor, antes de se dirigir à sala de aula, espera o tempo passar com 'bate-papos'.

12 São aulas interdisciplinares. Os professores que lecionam disciplinas afins elegem um assunto comum e organizam juntos, para o mesmo nível de ensino, um debate em torno do tema escolhido. Essas aulas geralmente ocorrem uma vez a cada quinzena.

13 Considerando que a escola não dispõe de funcionários suficientes para a realização das atividades burocráticas, a direção solicita aos docentes que as façam, como, por exemplo, realizar matrícula, preencher mapas de aprendizagem ou participar dos projetos indicados pela Secretaria Municipal de Educação e Cultura (SMEC). Esses acordos não só trazem benefícios ao funcionamento da escola como também para o(a) professor(a). Se este(a) necessitar faltar às aulas, tanto terá auxílio de um colega que realizará atividades com os alunos, para que estes não fiquem sem aula, como também contará com o apoio da direção, que não registrará a falta e ainda poderá não exigir atestados médicos que justifiquem a ausência.

14 As festividades são: Dia do Estudante, Semana da Criança, Dias das Mães, Dia do Professor, Natal etc.; comemorar aniversários da direção ou de um professor querido; ou, 
simplesmente, almoçar juntos na escola ou num restaurante. Este último diminui o desgaste e o custo, já que não há deslocamento para almoçar em casa, além de fortalecer os laços socioafetivos entre colegas.

15 Termo cunhado por Hannah Arendt, em seu livro Eichman em Jerusalém, apropriado por Dejours para analisar a banalização da injustiça social.

\section{Referências}

BARROS, Maria Elizabeth Barros de. Saúde, trabalho e processo de subjetivação nas escolas. In: Psicologia: Reflexão e Crítica, v. 15, n. 3, v 15, p. 24-52, 2002.

BOGDAN, Robert C.; BIKLEN, Sari Knopp. 1994. Investigação qualitativa em educação: uma introdução à teoria e aos métodos. Porto: Porto Editora, 1994.

CANGUILHEM, Georges. O normal e o patológico. 5. ed. Rio de Janeiro: Forense Universitária, 2000.

COSTA, Marisa C. Vorraber. Trabalho docente e profissionalismo. Porto Alegre: Sulinas, 1995.

DEJOURS, Christophe. A loucura do trabalho: estudos de psicopatologia do trabalho. 5. ed. São Paulo: Cortez, 1992.

Uma nova visão do sofrimento humano nas organizações. In: TORRES, Ofélia
Lanna Sette (Org.). O individuo nas organizações: dimensões esquecidas. 3. ed. São Paulo: Atlas, 1996.

HELMAM, Cecil G. 1994. Cultura, saúde e doença. 2. ed. Porto Alegre: Artes Médicas, 1994.

NEVES, Mary Yale; ATHAYDE, Milton. Saúde, gênero e trabalho na escola: um campo de conhecimento em construção. In: BRITO, Jussara Cruz de; ATHAYDE, Milton; NEVES, Mary Yale (Orgs.). Saúde e trabalho na escola. Rio de Janeiro: Cesteh/Ensp/ Fiocruz, p. 23-35, 1998.

NORONHA, Maria Márcia Bicalho; ASSUNÇÃO, Ada Ávila; OLIVEIRA, Dalila Andrade. O sofrimento no trabalho docente: o caso das professoras da rede pública de Montes Claros, Minas Gerais. Trabalho, Educação e Saúde, v. 6 n. 1, p. 65-86, mar./jun. 2008. Disponível em: <www.revista.epsjv.fiocruz.br>. Acesso em: 7 jul. 2008.

Recebido em 26/03/2008

Aprovado em 23/07/2009 